\title{
Neoplastic imitators of small bowel Crohn's disease
}

\author{
ANDREW D BADley, MD, RONALD E MACCORMICK, MD, FRCPC, G PAUl LEBRUn, MD, FRCPC
}

AD BADLEY, RE MACCORMICK, GP LEBRUN. Neoplastic imitators of small bowel Crohn's disease. Can J Gastroenterol 1992;6(2):77-83.

OBJECTIVE: To identify the problem of small bowel neoplasia masquerading as Crohn's disease. DATA AND METHODS: Sixteen articles reviewing the frequency of small bowel neoplasia were identified. Articles were selected if they assessed frequency of small bowel tumours in the general population. All articles were retrospective reviews of experience. Data on frequency were extracted and compiled. Three case reports as illustrative examples and a Medline search of small bowel neoplasms with manual searching of references from identified articles are presented. RESULTS: A total of 2507 cases of small bowel tumours was compiled. The frequency of tumours in decreasing order was adenocarcinoma, carcinoid, lymphoma, leiomyoma, leiomyosarcoma, adenoma and lipoma. CONCLUSIONS: Crohn's disease is the most prevalent disease affecting terminal ileum. Malignant disease may affect the terminal small bowel in ways which are clinically indistinguishable from Crohn's disease. Surgery is the last therapeutic option for Crohn's disease, whereas it is potentially curative and therefore the first option for small bowel neoplasia. Misdiagnosing malignant processes as being Crohn's disease causes delays in effective treatment and worsens prognosis.

Key Words: Crohn's disease, Small bowel neoplasia

\section{Imitateurs néoplasiques de la maladie de Crohn du grêle}

OBJECTIF: Identifier le problème de néoplasie du grêle se présentant comme une maladie de Crohn. DONNÉES ET MÉTHODES: Seize articles relatifs à la fréquence des néoplasmes du grêle ont été inventoriés. Ils ont été retenus quand ils évaluaient la fréquence des tumeurs du grêle dans la population générale. Tous étaient des analyses rétrospectives, dont les données ont été extraites et compilées. Trois observations ont servi d'exemples et les auteurs ont utilisé les références des articles publiés sur le sujet pour se constituer une bibliographie

Faculty of Medicine, Dalhousie University; and Departments of Medical Oncology and Radiology, Victoria General Hospital, Halifax, Nova Scotia

Correspondence and reprints: Dr Andrew D Badley, 1564 8-1/2 Street Southeast, Rochester, MN 55904, USA. Telephone (507) 255-6029, Fax (507) 255-6318

Received for publication January 16, 1992. Accepted February 3, 1992
$S_{\text {tid }}^{\mathrm{w}}$ MALL BOWEL NEOPLASIA IS A RELA. ively infrequent gastrointestinal tumour despite the large surface area of the small bowel. Numerous different histological types of small bowel neoplasms exist, and the incidence of the less common tumour types is significant.

The diagnosis of Crohn's disease usually is made on the basis of clinical and radiographical findings in addition to treatment response. Unfortunately, the most frequent area of involvement is the distal small bowel which often is inaccessible to biopsy without surgery. Surgery is not appropriate in the early evaluation of patients with suspected uncomplicated Crohn's disease. Since histological confirmation often is impossible, the diagnostic armamentarium is limited and the door to misdiagnosis is opened. This study concentrates on the neoplastic imitators of Crohn's disease of the small bowel.

\section{CASE ONE}

A 30 -year-old woman presented to her family doctor with a several month history of fatigue, nausea and crampy periumbilical abdominal pain. She was diagnosed with Crohn's disease and began treatment with azathioprine and prednisone. The patient's symptoms promptly resolved, but within two 
médicále pertinente à l'aide de Medline. RÉsultats: On a relevé 2507 cas de tumeurs du grêle - adénocarcinomes, carcinoïdes, lymphomes, léiomyomes, léiomyosarcomes, adénomes et lipomes, par ordre décroissant. CONCLUSIONS: La maladie de Crohn est l'affection la plus fréquente de l'iléon terminal. Les atteintes malignes du grêle peuvent donner un tableau clinique identique à celui de la maladie de Crohn. Mais si la chirurgie est la dernière option thérapeutique pour cette dernière, elle peut guérir la néoplasie du grêle, pour laquelle elle constitue le premier choix thérapeutique. Le diagnostic erroné d'une néoplasie maligne du grêle peut donc retarder le recours à une intervention efficace et assombrir le pronostic.

months her crampy pain recurred, intensified and shifted to the right lower quadrant. She also developed night sweats and a bowel habit of four or five loose, watery bowel movements daily.

On admission to hospital, a vague mass was palpable in her right lower quadrant, and she had normocytic anemia, mild leukocytosis, guaiac positive stools and a positive tuberculin skin test. Pelvic ultrasound demonstrated a poorly defined mass in the right iliac fossa, consistent with a septic complication of Crohn's disease. Small bowel follow-through and peroral pneumocolon are shown in Figure 1.

At laparotomy, a $15 \times 8 \times 7 \mathrm{~cm}$ tumour was found to have eroded through the small bowel wall and to have involved regional lymph nodes. Pathology revealed mixed cellularity Hodgkin's disease, clinical stage IVB. Treatment consisted of five cycles of mechlorethamine, vincristine, procar- bazine, prednisone (MOPP), and the patient is well 14 years later. Prednisone may improve symptoms in a variety of diseases. When such improvement is shortlived, re-evaluation is warranted.

\section{CASE TWO}

A 51-year-old woman presented to her family doctor with a two-year history of crampy right lower quadrant abdominal pain. She had associated loose bowel movements up to five times daily, alternating with constipation. A gastroenterologist diagnosed her as having Crohn's disease, and she began treatment with sulphasalazine. She continued to do well for three years, with two to three flare-ups per year (all of which settled promptly with short courses of prednisone). When one episode was slower to settle, she had a small bowel follow-through and subsequent laparotomy (Figure 2).

A mass in her terminal ileum with associated peritoneal seeding was

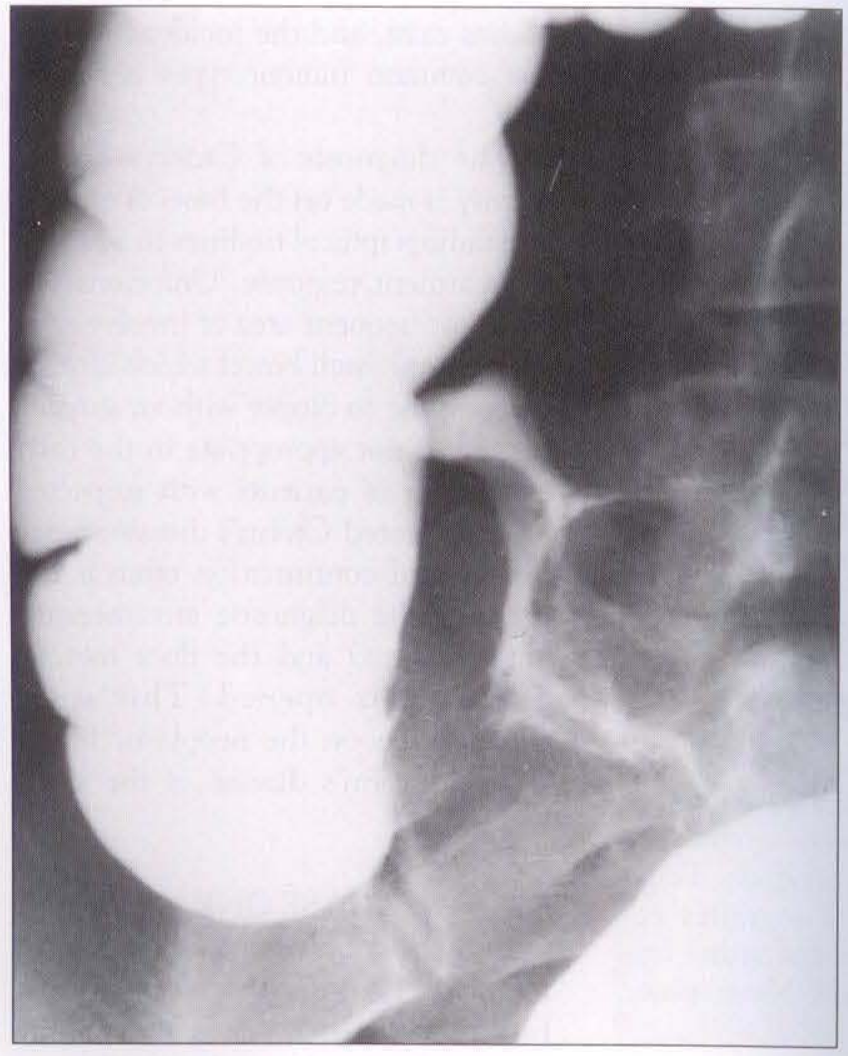

Figure 1) Above Spot film from barium enema showing narrow terminal ileum with nodular indentations. Right Spot film from small bowel follow-through with air in the colon (peroral pneumocolon) showing long segment of small bowel narrowing. The nodular indentations are less apparent

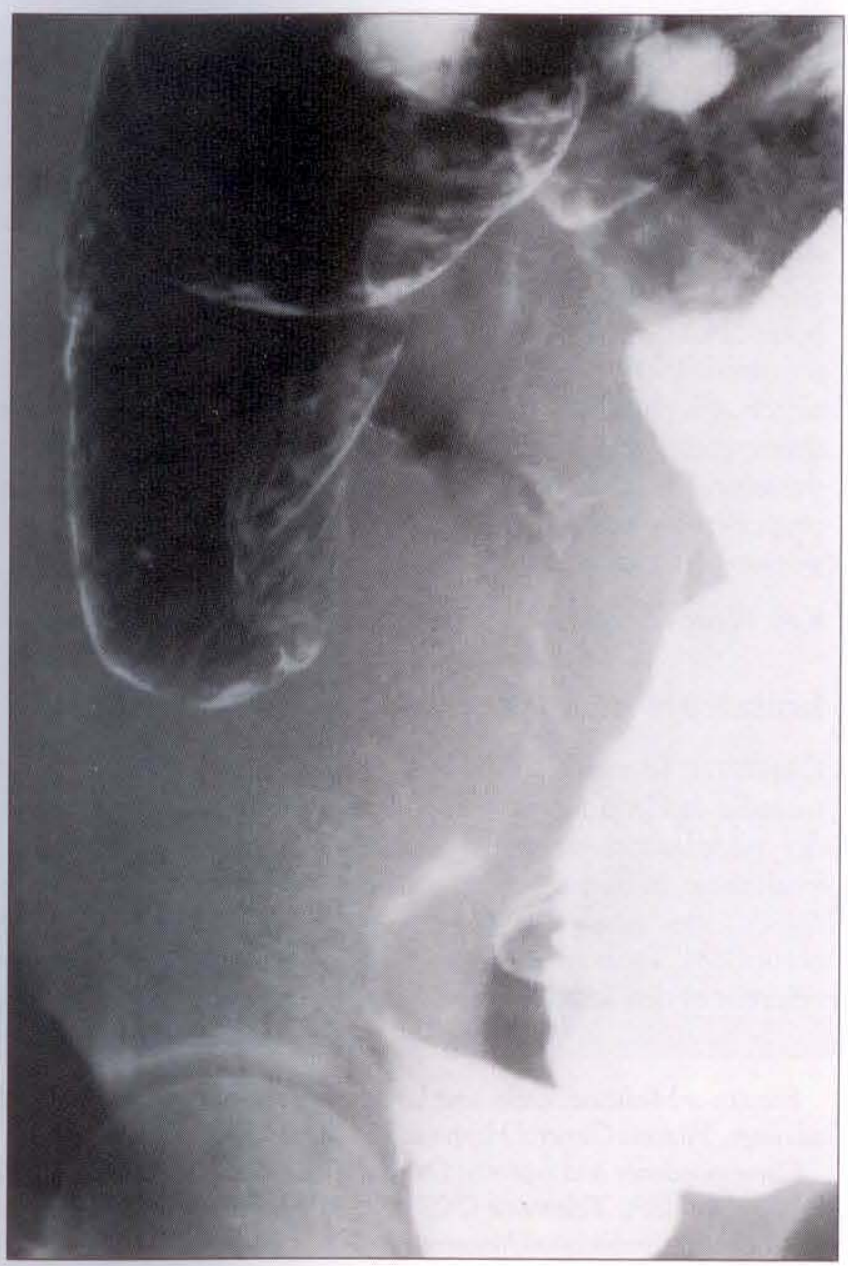




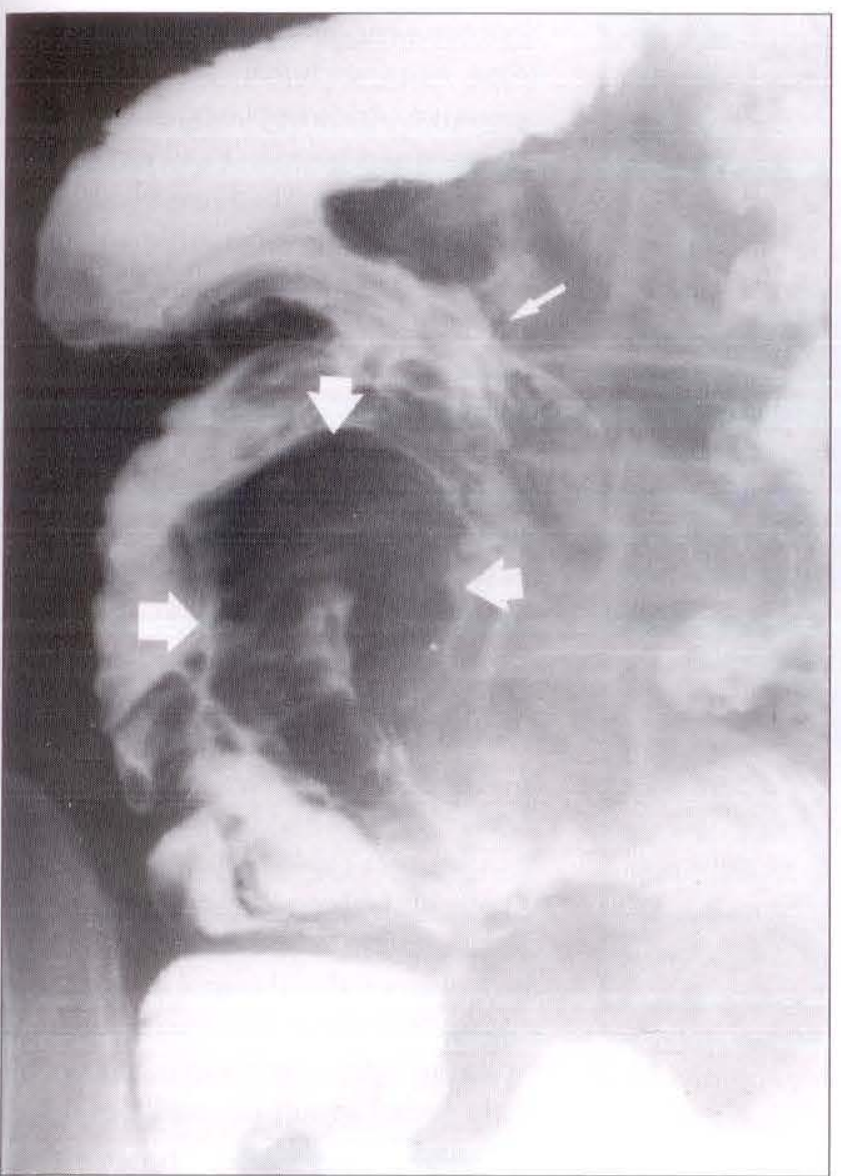

Figure 2) Above Spot film showing large ileocecal valve (large arrows) with deformity and angulation of the ascending colon (small arrow). Right Spot film from small bowel follow-through showing short segment of strictured terminal ileum (arrows). The mucosa proximally is normal

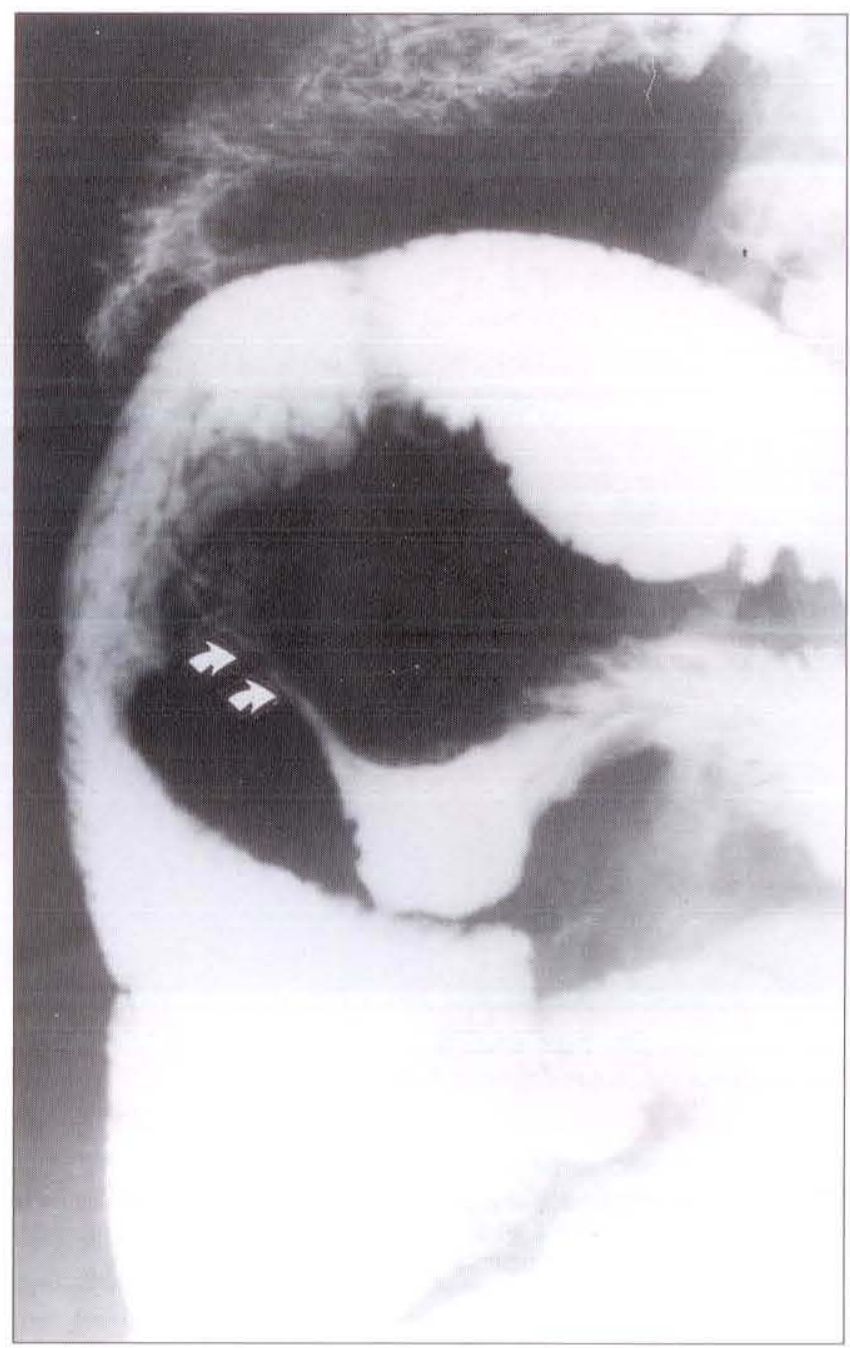

found, resected and subsequently proven to be a carcinoid tumour. The patient declined chemotherapy and is alive five years later. An abrupt change in the usual pattern of disease for a particular patient warrants reinvestigation.

\section{CASE THREE}

A 35-year-old female developed iron deficiency anemia during a pregnancy. When her anemia persisted after the termination of her pregnancy, she was seen by a gastroenterologist who diagnosed her as having ileocecal Crohn's disease (Figure 3).

Treatment consisted of 5-aminosalicylic acid and prednisone; however, within three months the patient was admitted for investigation of worsening right lower quadrant pain. Computed tomography scan, ultrasound and indium scan suggested abscess. At surgery, a $6 \times 5 \times 2 \mathrm{~cm}$ mass was resected from her ileocecum. Pathology revealed a poorly differentiated adenocarcinoma of the cecum which had eroded through the terminal ileum. All five sampled regional lymph nodes were involved.

The patient began treatment with 5-fluorouracil and levamasole, yet developed a pelvic side wall recurrence. This was resected but her disease again recurred. Because of her failing condition and evidence of distant metastases, the treatment objective was changed to palliative, and she died shortly thereafter. Unfortunately, neoplastic processes may mimic Crohn's disease.

\section{CROHN'S DISEASE}

Crohn's disease is a regional chronic inflammatory enteritis that most commonly involves the terminal ileum, but may occur anywhere from the mouth to the anus (1). Its incidence in the West appears to be increasing (2); whether this represents a true increase or increased clinician vigilance is uncertain. The prevalence in North America has been estimated at 10 to 70 per 100,000 (1) and the incidence has been estimated at five to seven per 100,000 per year (3).

The clinical presentation of Crohn's disease of the small bowel is varied and frequently nonspecific. Accordingly, radiology remains a major diagnostic tool. In contrast to patients with colonic Crohn's disease, plain film examination in patients with Crohn's disease of the small intestine is unrewarding (4) in the absence of obstruction or perforation. Small bowel follow-through with fluoroscopy is the most commonly used technique of small bowel examination at the authors' centre. In cases where small bowel follow-through does not adequately display the terminal ileum, 


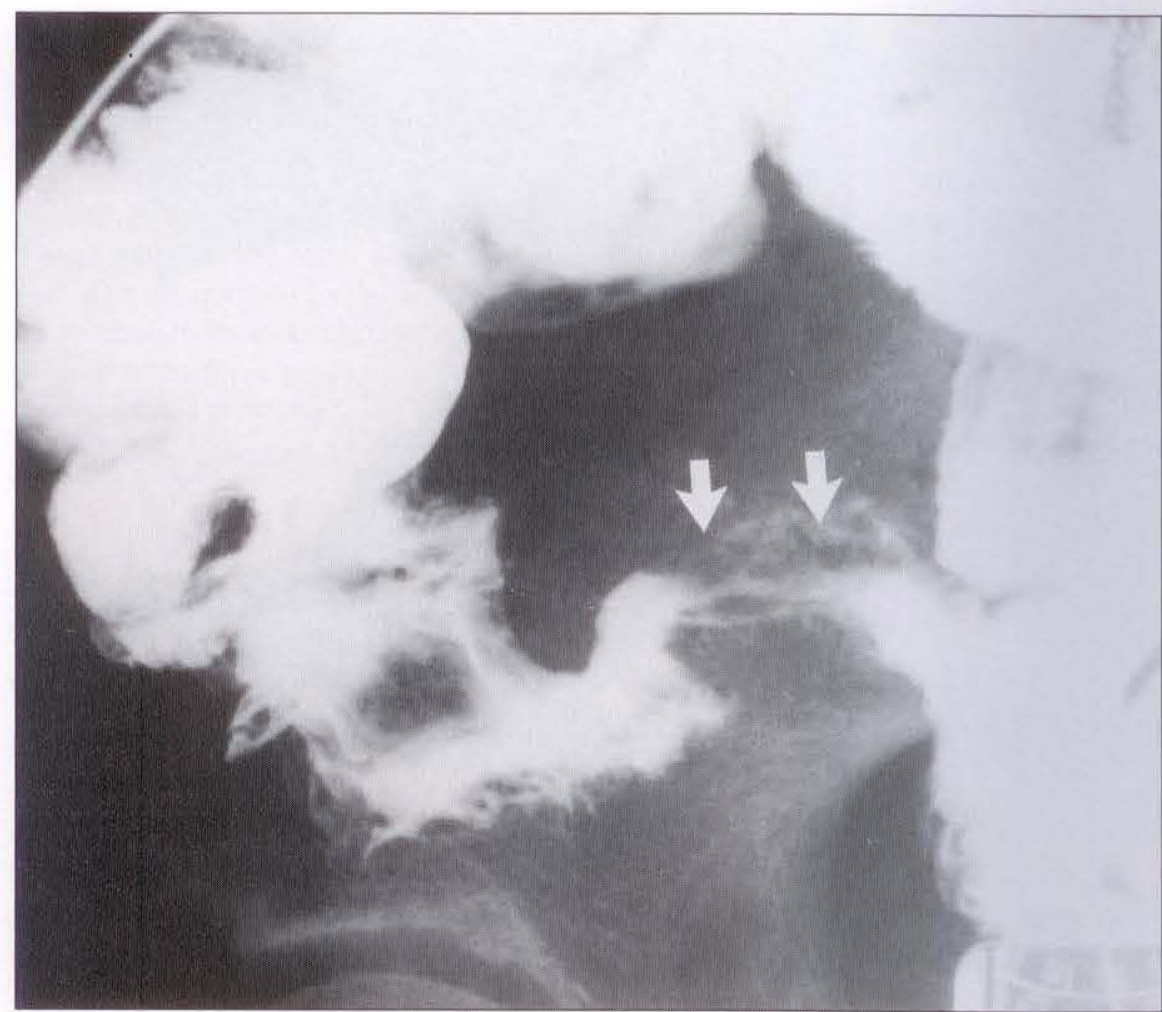

Figure 3) Spot film from small bowel follow-through showing narrowing of the terminal ileum (arrows) and the cecum deformed by tumour

\section{TABLE 1 \\ Differential diagnosis of Crohn's dis- ease involving the small bowel}

\section{Infectious \\ Viral \\ Bacterial \\ Mycobacterial \\ Fungal \\ Parasitic \\ Vascular/ischemic \\ Radiation \\ Endometriosis \\ Adjacent inflammatory disease \\ Appendicitis \\ Pelvic inflammatory disease \\ Neoplastic}

air contrast peroral pneumocolon (5) or enteroclysis (6) is used.

Early findings with small bowel follow-through include superficial erosions, aphthous ulcers and mucosal thickening or granulation. Later, cobblestoning, fissuring or ulceration may be seen. Luminal constriction is common, secondary to mucosal disease, mesenteric adenopathy or abscess formation. Atypical findings include dif- fuse small bowel involvement, relative ileal sparing, sharp angulation and large or multiple mass effect (4).

Ancillary radiographic procedures are used when the appearance is atypical, the diagnosis is in question or complications are suspected. Such procedures include computed tomography scanning (7), ultrasound (8) and radionucleotide imaging (9). Computed tomography scanning particularly is useful to demonstrate fistulous tracts (7) and thickened bowel walls. The most sensitive imaging technique is indium III granulocyte scanning. Measurements of fecal excretion of indium or of the scintigraphic fall in splenic activity are directly correlated with disease activity (10). Indium-labelled granulocytes localize diseased segments reproducibly and reliably (9). Ultrasound imaging can also be used reliably to assess disease extent. In one study, when rectal disease was excluded, ultrasound detected $91 \%$ of lesions that had been identified by indium scans (11).

Crohn's disease is incurable. Surgery is indicated only when medical management fails or complications occur.
Strictures can successfully be treated in some cases with balloon dilation, or operative stricturoplasty (12). When resection is required, the objective is to remove only overtly diseased segments with the smallest possible resection margins (no evidence exists that wider resection margins reduce recurrence) (13). Post resection recurrence virtually is inevitable and can be confirmed endoscopically at anastomotic sites in $85 \%$ of patients within three years of surgery. Clinical manifestations of recurrent disease occur at a cumulative rate of $10 \%$ per year (14). Surgey is delayed as long as possible.

\section{DIFFERENTIAL DIAGNOSIS}

The differential diagnosis of Crohn's disease is broad and must be considered at diagnosis (Table 1). Infectious causes represent the broadest group of Crohn's disease imitators and include viral, parasitic, bacterial and fungal causes. Neoplastic disease is less common, but represents the most serious and potentially lethal group of small intestinal diseases (Table 2).

\section{SMALL BOWEL TUMOURS}

Small bowel malignancies are strikingly rare. Despite its large surface area, the small bowel is responsible for less than $25 \%$ of all gastrointestinal neoplasms and less than $2 \%$ of malignant gastrointestinal tumours (15). Several theories have been presented to explain this low malignancy frequency. Proposed factors include rapid intestinal transit, high alkalinity, low bacterial populations (15) and the presence of intestinal hydroxylases (16). The putative effects of these factors are to decrease production, increase clearance and inactivate any potential carcinogens.

Numerous conditions are predisposing factors for small bowel cancer. Celiac sprue has been associated with lymphoma (17) and has been implicated in the pathogenesis of adenocarcinomas (18). Dermatitis herpetiformis has also been associated with a disproportionate number of small bowel adenocarcinomas (19). Crohn's disease patient's have a well-characterized increased risk of small intestinal aden. 
ocarcinoma compared with the general population $(20,21)$; patients with familial multiple polyposis syndromes have an increased risk of malignancy. Those with an increased risk of small bowel tumours include Gardner's syndrome (22) and Peutz-Jeghers syndrome (23). More recently, the acquired immune deficiency syndrome has been associated with gastrointestinal Kaposi's sarcoma (24) and gastrointestinal B cell lymphoma (25).

Tumours of the small bowel initially present with nonspecific symptoms of dyspepsia, anorexia, malaise and vague abdominal pain (15). These complaints are sufficiently common not to alarm attending physicians.

Later symptoms which prompt investigation include intermittent or partial small bowel obstruction, intussusception and overt or chronic blood loss (26). Malignant disease may present in the above ways, but also is associated with visceral pain, weight loss, nausea, vomiting and complete small bowel obstruction (27). A mass may frequently be palpated with malignant disease, but is uncommon with benign growths (28).

The key to small bowel neoplasm diagnosis is a high index of suspicion. Contrast radiography is the principal initial investigation, yet its sensitivity and specificity are low. The estimated diagnostic accuracy of small bowel follow-through in the diagnosis of small bowel malignancy is 50\% (29). Frequently techniques other than small bowel follow-through are required. One report identified 48 lesions missed by small bowel follow-through using enteroclysis (30). Adjunctive techniques include angiography, red blood cell scans and computed tomography scans (15). Angiography may help diagnosis and localize small bowel tumours. Tumour blush may be seen in vascular tumours, and displacement of the normal vascular pattern may be seen in hypovascular tumours. Actively bleeding lesions can be localized with angiography or red blood cell scans. Computed tomography scans are useful in defining the extent of disease and may predict resectability.

Laboratory investigations are not helpful in diagnosing small bowel neoplasms. Tumour markers have no role in diagnosis with the exception of carcinoid tumours which may elevate urinary 5-hydroxyindoleacetic acid. Other abnormal findings are nonspecific and reflect the overall health of the patient. Definitive diagnosis, therefore, is made by pathological examination of surgical (or rarely endoscopic) specimens. In the hands of a skilled colonoscopist, the ileocecal region frequently can be visualized, and occasionally the terminal ileum may be cannulated. If so, endoscopic biopsies can speed diagnosis.

Findings of 2507 cases of small bowel tumours reported in the literature between 1959 and 1986 are summarized in Table 3 (26,27,31-44). Because many reviews classified carcinoid tumours separately and did not differentiate between benign and malignant carcinoids, the current authors have followed suit. It is important to remember that carcinoid behaviour ranges from benign to malignant.

This compilation deals with small bowel tumours as a uniform group. The relative frequency, however, varies by site within the small bowel. For malignancies, adenocarcinoma is seen most commonly in the proximal small gut, and ileal disease is rare. The vast majority of carcinoids occur in the ileum and approximately half of small intestinal sarcomas are ileal. Lymphomas are almost nonexistent proximally, with 48 and $47 \%$ occurring in the ileum and jejunum, respectively (45).

The relative frequency of metastatic disease almost certainly is underrepresented by this summary. Only one of the studies reviewed (34) included metastatic disease in its series. The frequency in that series was $6.5 \%$ (seven of 104 cases) comprising three known metastases of melanosarcomatous origin, two metastases from gastrointestinal sources, one from lung and one of melanosarcomatous origin without a known primary. Metastases to the small bowel have been well-characterized and may be due to hematogenous, lymphangitic or transperitoneal spread (46). Metastases are most commonly from cervix, lung, esophagus, ovary and melanoma (47).

\section{TABLE 2 \\ Neoplasms which may mimic Crohn's disease of the small bowel}

Primary
Malignant
Lymphoma
Adenocarcinoma
Sarcoma
Intermediate
Carcinoid
Benign
Adenoma
Leiomyoma
Lipoma
Hemangioma

\section{Secondary}

Metastases

Lung

Gastrointestinal

Genitourinary

Melanoma

Peritoneal carcinomatosis

Adjacent cecal tumours

\section{TABLE 3 \\ Summary of 16 retrospective reviews of the relative frequency of small bowel tumours}

\begin{tabular}{|c|c|}
\hline $\begin{array}{l}\text { Small bowel } \\
\text { tumour type }\end{array}$ & Frequency (\%) \\
\hline \multicolumn{2}{|l|}{ Malignant } \\
\hline Adenocarcinoma & $691(27.5 \%)$ \\
\hline Lymphoma & $238(9.5 \%)$ \\
\hline Leiomyosarcoma & $166(6.5 \%)$ \\
\hline Sarcoma & $72(3 \%)$ \\
\hline Miscellaneous & $41(1.5 \%)$ \\
\hline Anaplastic & 9 (less than 1\%) \\
\hline Metastases & 7 (less than 1\%) \\
\hline Carcinoid & $649(26 \%)$ \\
\hline \multicolumn{2}{|l|}{ Benign } \\
\hline Leiomyoma & $226(9 \%)$ \\
\hline Adenoma & $126(5 \%)$ \\
\hline Lipoma & $113(45 \%)$ \\
\hline Hemangioma & $78(3 \%)$ \\
\hline Lymphangioma & 21 (less than 1\%) \\
\hline Neurofibroma & 18 (less than $1 \%$ ) \\
\hline Miscellaneous & 18 (less than $1 \%$ ) \\
\hline Fibroma & 17 (less than 1\%) \\
\hline Hamartoma & 8 (less than 1\%) \\
\hline Islet cell adenoma & 7 (less than 1\%) \\
\hline Endometrioma & 2 (less than 1\%) \\
\hline Total & 2507 \\
\hline
\end{tabular}

Based on references 26.27,31-44 
The four most frequently encountered malignancies were adenocarcinoma, carcinoid, lymphoma and leiomyosarcoma. Five-year survival rates for these tumours is grim, with the possible exception of lymphoma (its prognosis is dependent upon histology) Five-year survival from adenocarcinoma is $20 \%$ (47), and is $50 \%$ for both carcinoid (48) and leiomyosarcoma (43). Of course the major predictor of survival is disease extent (both microscopic and macroscopic) at diagnosis, thereby implying increased survival with earlier diagnosis and treatment.

\section{DISCUSSION}

Disease of the small bowel can present in a limited number of ways. Clinical signs and symptoms, and radiographic and laboratory findings are nonspecific and cannot reliably distinguish Crohn's disease from malignancy.

Differentiation between Crohn's disease and cancer is essential because treatment and prognosis are drastically different. The mainstay of Crohn's disease therapy is medical, with surgery being noncurative and used only in cases of medical management failure or in the presence of complications. This contrasts the primary role of surgery in the treatment of small bowel neoplasia in which surgery offers a potential cure.

\section{REFERENCES}

1. Donaldson RM. Crohn's disease. In: Sleisenger MH, Fordtran JS, eds. Gastrointestinal Disease:

Pathophysiology, Diagnosis and Management, 4th edn. Philadelphia: Saunders \& Co, 1989

2. Farmer RG, Hawk WA, Turnbull RG. Clinical patterns in Crohn's disease: A statistical study of 615 cases. Gastroenterology 1975;68:627-35.

3. Ekbom A, Helmick C, Zack M, Hans Olov A. The epidemiology of inflammatory bowel disease: A large population based study in Sweden. Gastroenterology 1991;100:350-8.

4. LeBrun GP. Pitfalls in the radiologic diagnosis of inflammatory bowel disease. Can J Gastroenterol 1990;4:317-23.

5. Bartram CI, Preston DM, LennardJones JE. The 'air enema' in acute colitis. Gastrointest Radiol 1983;8:61-5.

6. Ott DJ, Chen YM, Gelfand DW, van
If a misdiagnosis is made, the prognosis is worsened by the resultant delay in definitive treatment.

The incidence of Crohn' disease is five to seven per 100,000 (3), whereas the incidence of small bowel neoplasia, when considered as a single entity, is 0.7 to 1.6 per 100,000 (47). If only terminal ileal neoplasia is considered, the difference would be greater. Since Crohn's disease is chronic, and patients with small bowel neoplasms are either cured or die, the differences in prevalence is even greater. Therefore, the statistically probable diagnosis of a patient with undiagnosed terminal ileal disease is Crohn's disease. For this reason, it is tempting to diagnose any patient who has abdominal pain and terminal changes with Crohn's disease. The researchers contend that in the absence of histology, diagnosis of Crohn's disease should be one of exclusion - forcing the clinician to consider processes which may mimic Crohn's disease.

The authors have presented three cases of small intestinal disease which initially masqueraded as Crohn's disease, but subsequently were proved to be malignant. These cases demonstrate the need for diagnostic re-evaluation when response to treatment does not follow a predicted course.

It is not clear how final outcomes

Swearingen F, Munitz HA. Detailed per oral small bowel examination versus enteroclysis. Radiology 1985;155:29-34.

7. Fishman EK, Wolf EJ, Jones B, et al. CT evaluation of Crohn's disease: Effect on patient management. Am J Roentgenol 1987;148:534-7.

8. Kaftori JK, Pery M, Kleinhaus U. Ultrasonography in Crohn's disease. Gastrointest Radiol 1984;9:137-42.

9. Saverymottu SH, Camilleri M, Rees H, Levander JP, Hodgson HJF, Chadwick VS. Indium III-granulocyte scanning in the assessment of disease extent and disease activity in inflammatory bowel disease. A comparison with colonoscopy, histology, and fecal indium III-granulocyte excretion. Gastroenterology 1986;90-1121-8

10. Loreal O, Moisan A, Bretagne JF. Scintigraphic assessment of indium III labelled granulocyte splenic pooling: A new approach to inflammatory bowel disease activity. may have been altered by earlier recognition of the final diagnosis; conceptually at least, earlier demonstration of malignant disease may have led to more effective treatment with potentially reduced suffering, morbidity and mortality.

The intention of this paper is not to suggest that all patients with atypical presentations or disease courses undergo surgery for diagnosis, but rather to point out the need for careful scrutiny in accepting the diagnosis of Crohn's disease when histology is absent.

The authors have summarized reviews of the past 30 years to provide some insight into the relative frequency of neoplastic diseases of the small bowel, demonstrating a preponderance of carcinoid and adenocarcinoma when the small bowel was considered as a whole. The terminal ileum alone has a different spectrum of disease, with the majority of tumours being carcinoid, followed closely by sarcoma, lymphoma and adenocarcinoma.

Prognosis for all of these tumours is affected greatly by extent of disease at diagnosis. The consequences of a delay in diagnosis, therefore, are enormous, and the need for clinician awareness of neoplasia as a Crohn's disease imitator cannot be overemphasized.

J Nucl Med 1990;31:1470-3.

11. Khaw KT, Saverymuttu SH, Joseph

AE. Correlation of III indium scintigraphy with ultrasound in the detection and assessment of inflammatory bowel disease. Clin Radiol 1990;42:410-3.

12. Alexander Williams J. Inflammatory bowel disease revisited: Surgery today and tomorrow. Scand J Gastroenterol 1990;25(Suppl 175):107-12.

13. McLeod RS. Resection margins and recurrent Crohn's disease.

Hepatogastroenterology 1990;37:63-6.

14. Sachar DB. The problem of post operative recurrence in Crohn's disease. Med Clin North Am 1990;74:183-8.

15. Ashley SW, Wells SA. Tumors of the small intestine. Semin Oncol 1988; 15:116-28.

16. Wattenburg LW. Studies of polycyclic hydrocarbon hydroxylase of the intestine, possibly related to cancer. Cancer 1979;28:99-106. 
17. Loughran TP, Radin ME, Joachim-Deeg H. T cell intestinal lymphoma associated with celiac sprue. Ann Intern Med 1986;104:44-6.

18. Petreshock EP, Pessah M, Menachemie E. Adenocarcinoma of the jejunum associated with non tropical sprue. Am J Dig Dis 1975;20:796-802.

19. Gjone E, Nardoy A. Dermatitis herpetiformis, steatorrhea and malignancy. Br Med J 1970;1:610.

20. Senay E, Sachar DB, Keohane M, Greenstein AJ. Small bowel carcinoma in Crohn's disease. Distinguishing features and risk factors. Cancer 1989;63:360-3.

21. Richerds ME, Rickert RR, Nance FC. Crohn's disease associated carcinoma. A poorly recognised complication of inflammatory bowel disease. Ann Surg 1989;209:764-73.

22. Burt RW, Berensen MM, Lee RG, et al. Upper gastrointestinal polyps in Gardner's syndrome. Gastroenterology 1984:86:295-301.

23. Reid JD. Intestinal carcinoma in the Peutz-Jeghers syndrome. JAMA 1974;229:833-4.

24. Freidman S, Wright T, Altman D. Gastrointestinal kaposis sarcoma in acquired immunodeficiency syndrome: Endoscopic and autopsy findings. Gastroenterology 1985;89:102-8.

25. Levine AM, Meyer PR, Begandy MK, et at. Development of B cell lymphoma in homosexual men, clinical and immunological findings. Ann Intern Med 1984;100:7-13.

26. Darling RC, Welch CE. Tumors of the small intestine. $\mathrm{N}$ Engl J Med 1959;260:397-408

27. Zollinger RM, Sternfield WC, Schreiber H. Primary neoplasms of the small intestine. Am J Surg

1986;151:654-8.

28. Garvin PJ, Herman V, Kaminski DL, Willman VL. Benign and malignant tumors of the small intestine. In: Hickey RC, ed. Current Problems in Cancer, vol 3. Chicago: Year Book Medical, 1979.

29. Silberman H, Crichlow RW, Caplan HS. Neoplasms of the small bowel. Ann Surg 1974;180:157-61.

30. Maglinte DDT, Hall R, Miller RE, et al. Detection of surgical lesions of the small bowel by enteroclysis. Am J Surg 1984;147:225-9.

31. Wilson JM, Melvin DB, Gray GF, Thorbjarnarson B. Primary malignancies of the small bowel: A report of 96 cases and a review of the literature. Ann Surg 1974; 180:175-80.

32. Silberman H, Crichlow RW, Caplan HS. Neoplasms of the small bowel. Ann Surg 1974;180:157-61.

33. Hancock RJ. An 11 year review of primary tumors of the small bowel including the duodenum. Can Med Assoc J 1970;103;1177-9.

34. Garin ,C Lanatis G, Rousta B, Saegesser F. Anatomoclinical review of 104 cases of small intestinal tumor. Int Surg 1976;61518-26.

35. Wilson JM, Melvin DB, Gray GF, Thorbjarnarson B. Benign small bowel tumors. Ann Surg 1975;247-50.

36. Freund H, Lavi A, Pfefferman R, Durst AL. Primary neoplasms of the small bowel. Am J Surg 1978;135:757-91.

37. Rochlin B, Longmire WP. Primary tumors of the small intestine. Surgery 1961;5:586-92.

38. Braasch JW, Denbo HE. Tumors of the small intestine. Surg Clin North Am 1964:44:791-809.

39. Martin R. Malignant tumors of the small intestine. Surg Clin North Am 1986;66:779-55.

40. Cohen A, McNeill D, Terz JJ, Lawrence V. Neoplasms of the small intestine. Am J Dig Dis 1971;16:815-24.

41. Pagtalunan RJG, Mayo CW, Dockerty MB. Primary malignant tumors of the small intestine. Am J Surg 1964;108:13-8.

42. Barclay THC, Schapira DV. Malignant tumors of the small intestine. Cancer 1983;51:878-81.

43. Herbsman $H$, Wetstein D, Rosen $Y$, et al. Tumors of the small intestine. In: Ravitch MM, ed. Current Problems in Surgery, vol 17. Chicago: Yearbook Medical, 1980

44. Coutsoftides T, Shibata HR. Primary malignant tumors of the small intestine. Dis Colon Rect 1979;22:24-6.

45. Bresalier RS, Kim Y. Malignant neoplasms of the large and small intestine in gastrointestinal disease. In: Sleisenger MH, Fordtran JS, eds. Pathophysiology Diagnosis and Management, 4th edn. Philadelphia: Saunders \& Co, 1989.

46. Farmer RG, Hawk WA. Metastatic tumors of the small bowel. Gastroenterology 1964;47:496-504.

47. Sindelar WF. Cancer of the small intestine. In: DeVita VT, Hellman S, Rosenburg SA, eds. Principles and Practice of Oncology, 3rd edn. Philadelphia: Lippincott Co, 1989.

48. Goodwin JD. Carcinoid tumors: An analysis of 2837 cases. Cancer 1977;36:560-9. 


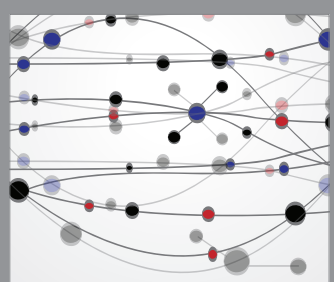

The Scientific World Journal
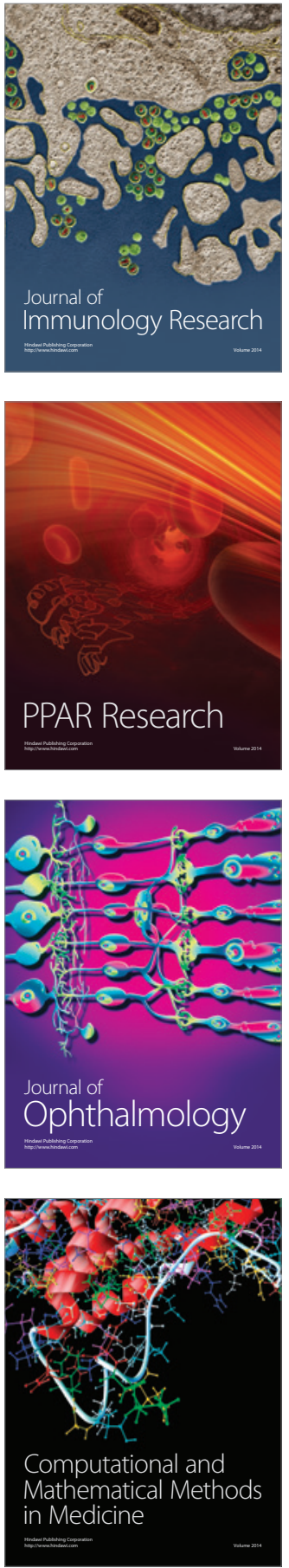

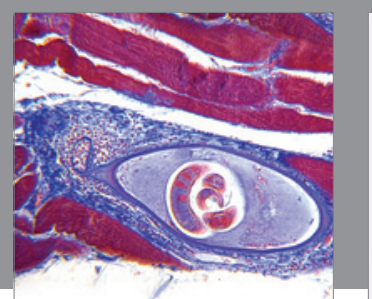

Gastroenterology Research and Practice

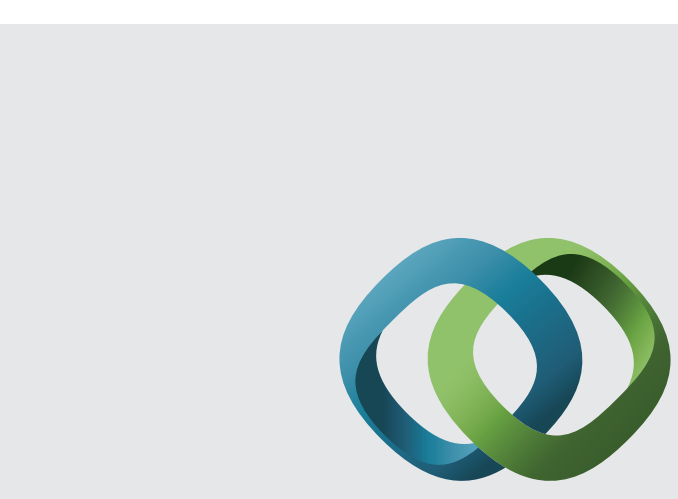

\section{Hindawi}

Submit your manuscripts at

http://www.hindawi.com
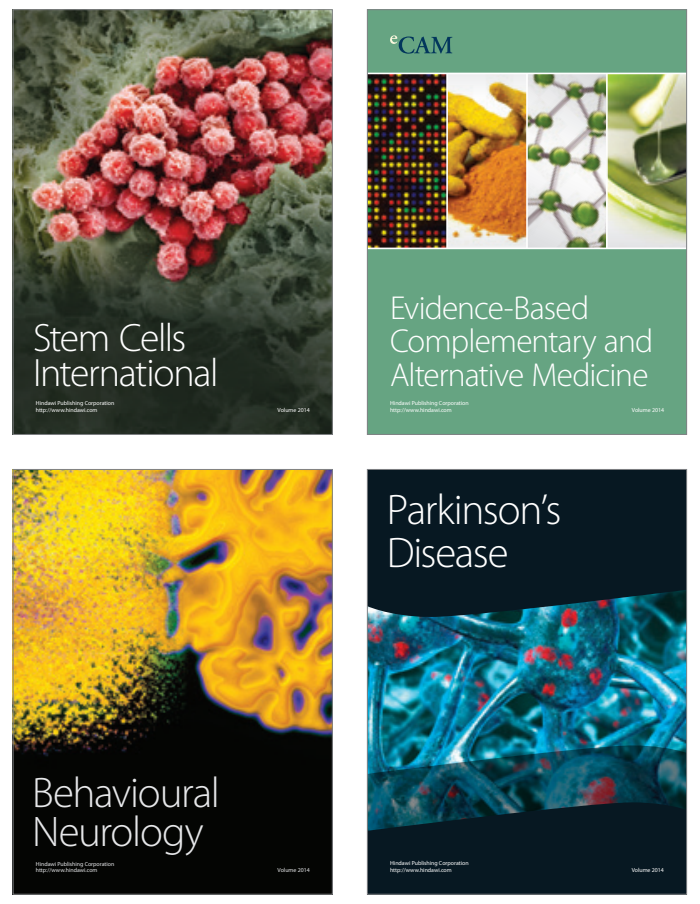
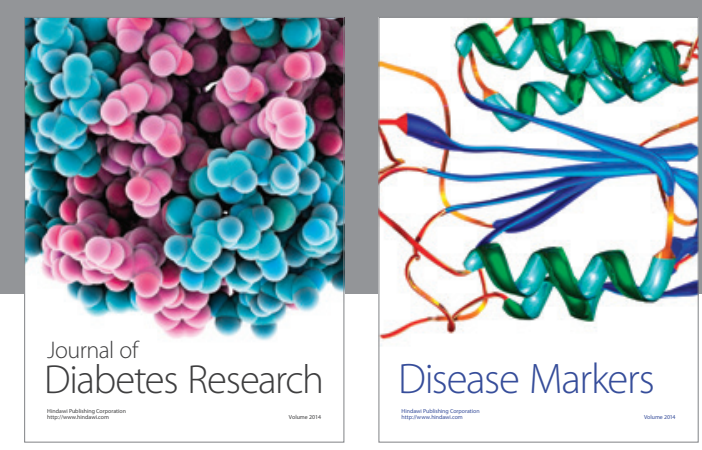

Disease Markers
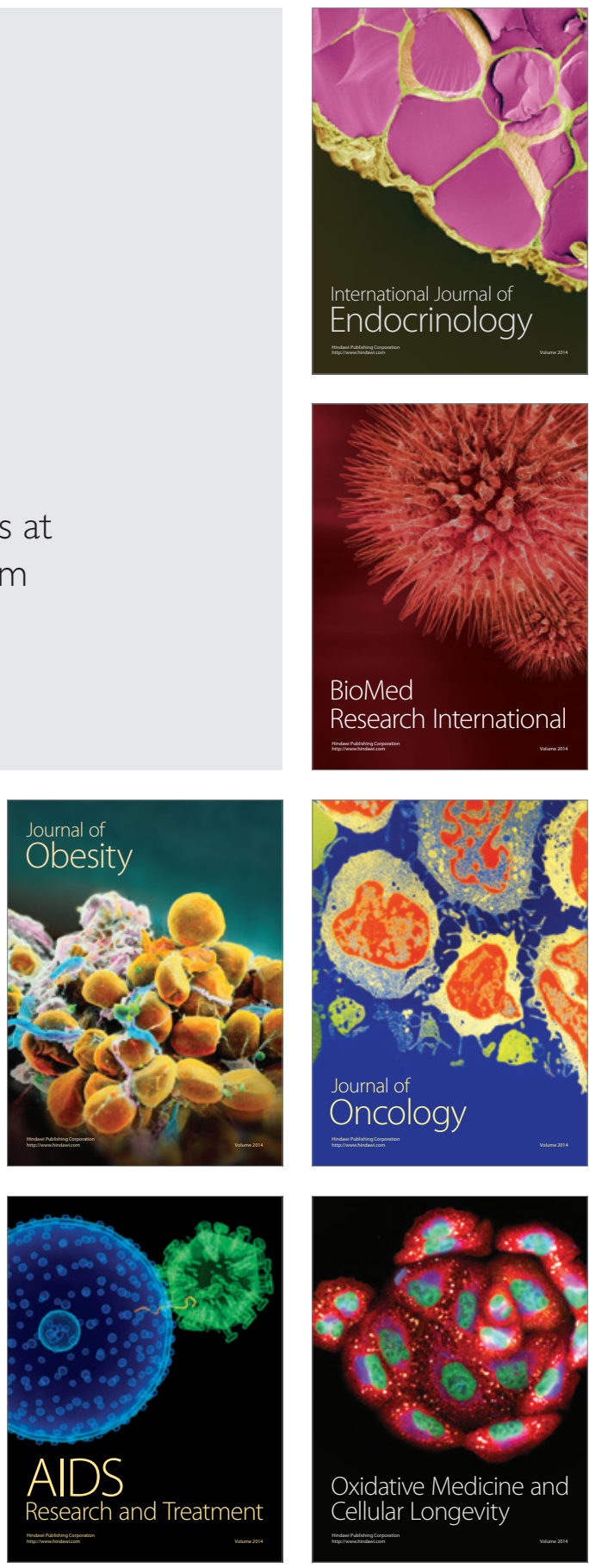